\title{
Associations between fatigue and physical capacity in people moderately affected by rheumatoid arthritis
}

\author{
Ingrid Demmelmaier $^{1}$ (D) . Susanne Pettersson ${ }^{1,2}$ (D) Birgitta Nordgren $^{1,3}$ (D) Alyssa B. Dufour ${ }^{1,4,5}$ (D) \\ Christina H. Opava ${ }^{1,6}$
}

Received: 5 July 2018 / Accepted: 20 August 2018 / Published online: 29 August 2018

(c) The Author(s) 2018

\begin{abstract}
To explore the contribution of physical capacity in explaining variations in fatigue among people with rheumatoid arthritis (RA). This study included participants recruited for a physical activity intervention. Data were collected from the Swedish Rheumatology Quality Registers, from questionnaires on fatigue, activity limitation, perceived health, pain and anxiety/ depression and from physical capacity tests (lower limb function, grip strength, and aerobic capacity). We used logistic regression to estimate the association between severe fatigue ( $\geq 50$, visual analogue scale $0-100)$ and (A) independent variables related to disease and disease impact and (B) model A plus physical capacity tests. Pooled odds ratio tests compared model fit. Out of the 269 participants (mean age 60 years, mean disease activity score [DAS28] 2.8), severe fatigue was reported by $35 \%$. The three variables which were statistically significantly associated with severe fatigue $(p<0.05)$ in both models were perceived health, pain and anxiety/depression. Anxiety/depression demonstrated the largest effect size with odds ratios of $2.43(95 \%$ CI 1.20, 4.94) in model A and 2.58 (95\% CI 1.25, 5.32) in model B. The likelihood ratio test indicated that model B was a better fit to the data than model A with $X^{2}(d f 3)=2.65, p=0.048$. Severe fatigue in people with RA is associated with self-rated health, pain and anxiety/depression rather than with physical capacity. Future studies should be prospective, use multidimensional assessments of fatigue to explore the influence of physical capacity and control for possible influence of comorbidities associated with fatigue.
\end{abstract}

Keywords Aerobic capacity · Fatigue $\cdot$ Grip strength $\cdot$ Lower limb function $\cdot$ Physical capacity $\cdot$ Rheumatoid arthritis

Ingrid Demmelmaier and Susanne Pettersson equally contributed to this work.

Susanne Pettersson

susanne.pettersson@sll.se

Ingrid Demmelmaier

ingrid.demmelmaier@ki.se

Birgitta Nordgren

birgitta.nordgren@ki.se

Alyssa B. Dufour

AlyssaDufour@hsl.harvard.edu

Christina H. Opava

christina.opava@ki.se

1 Division of Physiotherapy, Department of Neurobiology, Care Sciences and Society, Karolinska Institutet, Stockholm, Sweden

\section{Introduction}

Rheumatoid arthritis (RA) is an inflammatory disease and its impact on patients is traditionally categorized in high, moderate, low or remission as captured by a disease activity

2 Theme Inflammation and Infection, Karolinska University Hospital, 14186 Stockholm, Sweden

3 Functional Area Occupational Therapy and Physiotherapy, Allied Health Professionals' Function, Karolinska University Hospital, Stockholm, Sweden

4 Harvard Medical School, Institute for Aging Research, Hebrew Senior Life, Boston, MA, USA

5 Beth Israel Deaconess Medical Center, Boston, MA, USA

6 Rheumatology Clinic, Karolinska University Hospital, Stockholm, Sweden 
score [1]. Disease impact reflected as activity limitation can be stratified based on the Health Assessment Questionnaire (HAQ) [2]. Additional aspects of RA impact can be captured as general health perception or quality of life [3]. With modern medical treatment disease impact seems to be less prominent [4], but several disease aspects, e.g., fatigue and pain, still impair patients' daily life despite low-disease activity [5].

Fatigue is one of the most prominent problems in people with rheumatic diseases and has often a detrimental effect on their quality of life [6]. Fatigue may be peripheral or central [7] with the former deriving from neuromuscular dysfunction related to impaired neurotransmission in the peripheral nerves and/or deficits in muscular contraction, and the latter described as abnormalities in neurotransmitter pathways within the central nervous system (CNS). Central fatigue is presumably more frequent in people with chronic conditions and more influenced by psychological complaints.

A theoretical model of fatigue in RA suggests that several interrelated factors contribute to the experience and burden of fatigue [8]. The model includes disease-related factors, such as pain or inflammation, as drivers of fatigue. However, the most evident correlates of fatigue are pain, physical impairment and depression [9], with depression suggested as a mediator influenced by disease activity [10]. Furthermore, pain and fatigue often mutually influence and interfere with each other [11]. Hence, pain may also explain, to some extent, conflicting reports on correlations between fatigue and disease activity in RA [12].

Physical activity, including planned and structured exercise, is an important non-pharmacological intervention that positively affects fatigue in RA [13, 14]. Additionally, physical activity also positively influences disease activity [15], aerobic capacity and muscle strength [16], pain, activity limitation and health-related quality of life [16]. Furthermore, qualitative aspects of physical activity have been described in terms of joy, wellbeing and satisfaction, identification with wellness rather than illness and expanding social networks [17]. Thus, the influence of physical activity on fatigue might be a mix of biological, physical and psychosocial benefits. To our knowledge, only one previous study has explored the relative impact of a comprehensive set of such determinants on fatigue in RA. Aerobic capacity was the only physical capacity test included and did not explain the variance in fatigue, which was mainly explained by depression [18]. Not only aerobic capacity but also muscle strength and lower limb capacity, are modifiable and their relative contributions to fatigue are thus of interest to better understand and address this detrimental consequence of RA.

The aim of the present study was to explore the contribution of physical capacity (aerobic capacity, grip strength and timed standing) in explaining variations of fatigue among people with RA in addition to predictors previously identified.

\section{Materials and methods}

\section{Design and participants}

This cross-sectional study used baseline assessment data from 269 people diagnosed with RA according to the American Rheumatism Association criteria [19] who had agreed to participate in a 2-year support program for health-enhancing physical activity (HEPA) [20]. The study sample, for which the selection procedure has previously been described in detail [21], was derived from a larger sample identified from six rheumatology clinics via the Swedish Rheumatology Quality Registers (SRQ) [22]. The participants of the present sample were 18-75 years of age, independent in daily living (Stanford Health Assessment Questionnaire disability index, HAQ-DI $\leq 2$ ) [23], not physically active in line with HEPA guidelines [24], had good Swedish language skills and indicated interest to participate in a HEPA trial [21]. No additional exclusion criteria were applied.

\section{Assessment methods}

\section{Dependent variable}

Fatigue was rated on a $100 \mathrm{~mm}$ visual analogue scale (VAS) from 0 ("No fatigue") to 100 ("Maximal fatigue"). The fatigue VAS has good face validity and is sensitive for change in RA [25].

\section{Independent variables}

Sociodemographics Age and gender were retrieved from the SRQ, education (university or not) and living single or with others were self-reported in a questionnaire specifically designed for the present study.

Disease-related variables Disease duration (years since first symptoms), disease activity 28-joint count (DAS28) calculated on erythrocyte sedimentation rate (ESR), medication with disease-modifying antirheumatic drugs (DMARDs) (yes/no) and medication with biologics (yes/no) were retrieved from the SRQ and/or patient files. Comorbidities were defined as report of any of the categories "respiratory", "cardiovascular", "neurological" "psychiatric" disease, "diabetes mellitus" or "other".

Self-reported physical activity and anthropometrics Current HEPA (past week) was assessed by the International Physical Activity Questionnaire (IPAQ) - short version [26] and described as obtained or not, based on the IPAQ scoring protocol [27]. Maintained HEPA (past 6 months) 
was assessed by the exercise stage assessment instrument (ESAI) [28] and described as obtained or not. Body mass index (BMI) was calculated as body weight $(\mathrm{kg})$ divided by the square of body height $\left(\mathrm{m}^{2}\right)$.

Perceived disease impact Activity limitation was assessed by the Stanford Health Assessment Questionnaire-Disability Index (HAQ-DI) and ranged from 0 ("no activity limitation") to 3 ("totally dependent") [23]. Perceived health was rated on a $100 \mathrm{~mm}$ visual analogue scale (VAS) from 0 ("totally fine") to 100 ("worst imaginable health") and pain with VAS from 0 ("no pain") to 100 ("maximal pain") [29]. Anxiety/depression was assessed with one item from the EuroQol (EQ-5D-3L) ranging from 1 to 3, with 1 indicating "no problems" and 3 "extreme problems" [30]. The EuroQol is not a diagnostic tool, but rather captures the perception of distress.

Physical capacity Lower limb function was assessed with the timed-stands test (TST) and presented in seconds (s) [31] and average grip strength was assessed with the Grippit device (N) [32]. The mean of three 10-s grip force trials of the right hand was used for analyses. The results of lower limb function and grip strength tests were categorized into normal or below normal reference values [31, 32]. Maximal oxygen uptake $\left(\mathrm{ml} \times \mathrm{kg}^{1} \times \mathrm{min}^{1}\right)$ was estimated from a submaximal Åstrand and Rhyming bicycle ergometer test based on a linear relationship between mechanical load, oxygen uptake and heart rate obtained during the test [33].

\section{Data management and statistical analyses}

The dependent variable fatigue was categorized as low/moderate $(0-49 \mathrm{~mm})$ or severe $(50-100 \mathrm{~mm})$ as previously used in RA [12]. Descriptive statistics (means, standard deviations or proportions) were calculated for the total sample and stratified by level of fatigue. Multiple imputation (package MICE in R) was used to impute missing data among the independent variables [34]. Pooled odds ratios (OR) and 95\% confidence intervals (CI) for the univariate association between each independent variable and severe fatigue were calculated using pooled logistic regression (package MICE in R). Variables significantly associated with severe fatigue in univariate analyses $(p<0.1)$ were included in two adjusted logistic regression models: (A) including variables related to disease and disease impact (disease duration, biological drugs, comorbidities, activity limitation (HAQ-DI), perceived health, pain, anxiety/depression) and (B) including variables related to disease, disease impact and physical capacity (grip strength, lower limb function, aerobic capacity). Pooled odds ratios and $95 \%$ confidence intervals were calculated using pooled logistic regression (package MICE in R) and models A and B were compared using the pooled likelihood ratio test for multiple imputations [35]. An alpha level of 0.05 was used in the adjusted logistic regression models to indicate statistically significant results.

\section{Ethics}

The study was carried out in compliance with the Helsinki Declaration. Ethics approval was obtained from the Stockholm Regional Ethical Review Board. Participation was sought in a letter containing information about the study, and the participants consented by returning their questionnaires.

\section{Results}

The 269 participants had predominantly low/moderate disease activity and moderate impact of the disease (Table 1). A majority of the participants had normal lower limb function (76\%) and normal grip strength (74\%) according to age and gender match norm values. Participants' mean level of fatigue was 36 (SD 26) and 35\% $(n=95)$ were categorized as having severe fatigue $(\geq 50)$.

In the univariate analyses, significant associations $(p<0.1)$ between severe fatigue and disease duration, medication with biological drugs, presence of comorbidities, activity limitation, perceived health, pain, anxiety/depression and grip strength were found (Table 2).

Results from the two adjusted logistic regression models are presented in Table 3. The three variables which were statistically significantly associated with severe fatigue $(p<0.05)$ in both models were perceived health, pain and anxiety/depression. Anxiety/depression demonstrated the largest effect size with odds ratios of 2.43 (95\% CI 1.20, 4.94) in model A and 2.58 (95\% CI 1.25, 5.32) in model B. The likelihood ratio test indicated that model B was a better fit to the data than model A with $X^{2}(d f 3)=2.65, p=0.048$.

\section{Discussion}

To our knowledge, this is the first study investigating the explanation of fatigue by physical capacity, other than aerobic capacity. However, in contrast to our assumptions, we only found physical capacity to be marginally associated with severe fatigue in this sample moderately affected with RA. Its contribution was only indicated by better model fit by inclusion of physical capacity variables, whereas the previously known disease impact variables perceived health, pain and anxiety/depression consistently and significantly contributed to variations in fatigue.

The participants in the present study were moderately affected by RA, with more than half of them in remission or with low-disease activity. Additionally, a majority of our sample had normal lower limb function [31] and normal 
Table 1 Characteristics of the total sample and the subgroups with low/moderate fatigue (VAS $0-49$ ) and severe fatigue (VAS 50-100)

\begin{tabular}{|c|c|c|c|}
\hline & $\begin{array}{l}\text { Total } \\
\text { sample } \\
(n=269)\end{array}$ & $\begin{array}{l}\text { Subgroup with low/ } \\
\text { moderate fatigue } \\
(n=174)\end{array}$ & $\begin{array}{l}\text { Subgroup with } \\
\text { severe fatigue } \\
(n=95)\end{array}$ \\
\hline \multicolumn{4}{|l|}{ Sociodemographics } \\
\hline Age years, mean (SD) & $60(9)$ & $60(9)$ & $59(9)$ \\
\hline \multicolumn{4}{|l|}{ Gender } \\
\hline Female, $n(\%)$ & $220(82)$ & $139(80)$ & $81(85)$ \\
\hline Male, $n(\%)$ & $49(18)$ & $35(20)$ & $14(15)$ \\
\hline \multicolumn{4}{|l|}{ Education } \\
\hline No university, $n(\%)$ & $136(51)$ & $87(50)$ & $49(52)$ \\
\hline University, $n(\%)$ & $133(49)$ & $87(50)$ & $46(48)$ \\
\hline \multicolumn{4}{|l|}{ Other adults in household } \\
\hline No, $n(\%)$ & $62(23)$ & $38(22)$ & $24(25)$ \\
\hline Yes, $n(\%)$ & $205(76)$ & $135(78)$ & $70(74)$ \\
\hline \multicolumn{4}{|l|}{ Disease-related variables } \\
\hline Disease duration yrs, mean (SD) & $12(9)$ & $11(9)$ & $14(11)$ \\
\hline Disease activity DAS28 $0-10$, mean (SD) & $2.8(1.2)$ & $2.8(1.1)$ & $3.1(1.3)$ \\
\hline Remission $0-2.5, n(\%)$ & $89(33)$ & $65(37)$ & $24(25)$ \\
\hline Low $2.6-3.1, n(\%)$ & $38(14)$ & $22(13)$ & $16(17)$ \\
\hline Moderate $3.2-5.1, n(\%)$ & $61(23)$ & $38(22)$ & $23(24)$ \\
\hline High $5.2-10, n(\%)$ & $12(4)$ & $7(4)$ & $5(5)$ \\
\hline \multicolumn{4}{|l|}{ Medication DMARDs } \\
\hline No, $n(\%)$ & $49(18)$ & $33(19)$ & $16(17)$ \\
\hline Yes, $n(\%)$ & $163(61)$ & $106(61)$ & $57(60)$ \\
\hline \multicolumn{4}{|l|}{ Medication biological drugs } \\
\hline No, $n(\%)$ & $94(35)$ & $67(39)$ & $27(28)$ \\
\hline Yes, $n(\%)$ & $123(46)$ & $75(43)$ & $48(51)$ \\
\hline \multicolumn{4}{|l|}{ Comorbidities } \\
\hline No, $n(\%)$ & $116(43)$ & $82(47)$ & $34(36)$ \\
\hline Yes, $n(\%)$ & $153(57)$ & $92(53)$ & $61(64)$ \\
\hline \multicolumn{4}{|l|}{ Perceived disease impact } \\
\hline Activity limitation HAQ-DI $0-3$, mean (SD) & $0.5(0.5)$ & $0.4(0.4)$ & $0.8(0.5)$ \\
\hline No, $(0), n(\%)$ & $63(23)$ & $57(33)$ & $6(6)$ \\
\hline Yes, $(>0) n(\%)$ & $206(77)$ & $117(67)$ & $89(94)$ \\
\hline Health VAS 0-100, mean (SD) & $30(21)$ & $20(13)$ & 49 (19) \\
\hline Pain VAS 0-100, mean (SD) & $28(22)$ & $18(14)$ & $47(21)$ \\
\hline Fatigue VAS 0 -100, mean (SD) & $36(26)$ & $20(15)$ & $66(12)$ \\
\hline \multicolumn{4}{|l|}{ Anxiety/depression } \\
\hline EQ5D-3L 1-3, mean (SD) & $1.3(0.5)$ & $1.2(0.4)$ & $1.6(0.6)$ \\
\hline \multicolumn{4}{|l|}{ Self-reported physical activity } \\
\hline \multicolumn{4}{|l|}{ Current HEPA IPAQ } \\
\hline No, $n(\%)$ & $109(41)$ & $65(37)$ & $44(46)$ \\
\hline Yes, $n(\%)$ & $160(59)$ & $109(62)$ & $51(54)$ \\
\hline \multicolumn{4}{|l|}{ Maintained HEPA ESAI } \\
\hline No, $n(\%)$ & $228(85)$ & $148(85)$ & $80(84)$ \\
\hline Yes, $n(\%)$ & $38(14)$ & $23(13)$ & $15(16)$ \\
\hline \multicolumn{4}{|l|}{ Physical capacity and anthropometrics } \\
\hline Lower limb function TST s, mean (SD) & $22(9)$ & $22(7)$ & $23(12)$ \\
\hline Low, $n(\%)$ & $57(21)$ & $36(21)$ & $21(22)$ \\
\hline Normal, $n(\%)$ & $205(76)$ & $134(77)$ & $71(75)$ \\
\hline Grip strength Grippit $(N)$, mean (SD) & 194 (114) & $204(110)$ & $175(120)$ \\
\hline Low, $n(\%)$ & $69(26)$ & $32(18)$ & 37 (39) \\
\hline
\end{tabular}


Table 1 (continued)

\begin{tabular}{llll}
\hline & $\begin{array}{l}\text { Total } \\
\text { sample } \\
(n=269)\end{array}$ & $\begin{array}{l}\text { Subgroup with low/ } \\
\text { moderate fatigue } \\
(n=174)\end{array}$ & $\begin{array}{l}\text { Subgroup with } \\
\text { severe fatigue } \\
(n=95)\end{array}$ \\
\hline $\begin{array}{l}\text { Normal, } n(\%) \\
\text { Aerobic capacity Åstrand bicycle test, } \mathrm{ml} \times \\
\mathrm{kg}^{1} \times \min ^{1}, \text { mean }(\mathrm{SD})\end{array}$ & $28(8)$ & $141(81)$ & $57(60)$ \\
Body mass index kg/m $/ \mathrm{m}^{2}$, mean $(\mathrm{SD})$ & $28(8)$ & $28(9)$ \\
\hline
\end{tabular}

For perceived disease impact variables, high values indicate high impact

When percentages within variables do not add up to 100 , there are missing values

DAS28 Disease Activity Score 28, DMARDs disease-modifying antirheumatic drugs, HAQ-DI Stanford Health Assessment Questionnaire, VAS Visual Analogue Scale, EQ5D-3L euro quality of life 5 dimensions, $H E P A$ health-enhancing physical activity, IPAQ International Physical Activity Questionnaire, ESAI exercise stage assessment instrument, TST timed-stands test

Table 2 Univariate associations between potential predictors and being in the severe fatigue category

\begin{tabular}{|c|c|c|}
\hline & OR $(95 \% \mathrm{CI})$ & $p$ value \\
\hline \multicolumn{3}{|l|}{ Sociodemographics } \\
\hline Age, years & $0.99(0.96,1.02)$ & 0.446 \\
\hline Gender, male vs female & $0.69(0.35,1.35)$ & 0.277 \\
\hline Education university vs not university & $0.94(0.57,1.55)$ & 0.804 \\
\hline Other adults in household ${ }^{\mathrm{a}}$, yes vs no & $0.84(0.46,1.51)$ & 0.554 \\
\hline \multicolumn{3}{|l|}{ Disease-related variables } \\
\hline Disease duration, years & $1.02(1.00,1.05)$ & 0.080 \\
\hline Disease activity $^{\mathrm{a}} 0-10$ & $1.18(0.93,1.51)$ & 0.176 \\
\hline Medication DMARDs ${ }^{\mathrm{a}}$, yes vs no & $1.13(0.56,2.28)$ & 0.740 \\
\hline Medication biological drugs ${ }^{\mathrm{a}}$, yes vs no & $1.67(0.93,3.00)$ & 0.086 \\
\hline Comorbidities, yes vs no & $1.60(0.96,2.67)$ & 0.074 \\
\hline \multicolumn{3}{|l|}{ Perceived disease impact } \\
\hline Activity limitation $0-3$ & $5.40(3.05,9.54)$ & $<0.0001$ \\
\hline Health $^{\mathrm{a}} 0-100$ & $1.11(1.08,1.13)$ & $<0.0001$ \\
\hline Pain 0-100 & $1.08(1.06,1.10)$ & $<0.0001$ \\
\hline Anxiety/depression $1-3$ & $4.23(2.50,7.16)$ & $<0.0001$ \\
\hline \multicolumn{3}{|l|}{ Self-reported physical activity } \\
\hline Current HEPA, yes vs no & $0.69(0.42,1.15)$ & 0.153 \\
\hline Maintained $\mathrm{HEPA}^{\mathrm{a}}$, yes vs no & $1.17(0.58,2.37)$ & 0.658 \\
\hline \multicolumn{3}{|l|}{ Physical capacity and anthropometrics } \\
\hline Lower limb function ${ }^{\mathrm{a}}$ seconds & $1.02(0.99,1.05)$ & 0.159 \\
\hline Grip strength $^{\mathrm{a}}$ Newton & $1.00(1.00,1.00)$ & 0.053 \\
\hline Aerobic capacity ${ }^{\mathrm{a}} \mathrm{ml} \times \mathrm{kg}^{1} \times \min ^{1}$ & $0.99(0.96,1.03)$ & 0.653 \\
\hline Body mass index ${ }^{a} \mathrm{~kg} / \mathrm{m}^{2}$ & $1.02(0.97,1.08)$ & 0.389 \\
\hline
\end{tabular}

Odds ratios (OR) and $95 \%$ confidence intervals (CI) for 1 unit increase in each predictor

Abbreviations: see Table 1

${ }^{a}$ Multiple imputation for missing data

grip strength [36] and only 35\% of them reported severe levels of fatigue, which is comparably low [25]. Despite this, our results confirm previous findings demonstrating perceived health and pain as important contributors $[9$,
37] and previous results from studies with limited sample sizes suggesting that aerobic capacity does not contribute to explain self-reported levels of fatigue $[18,38]$. Our findings of very limited contribution of physical capacity in explaining severe fatigue might partly be explained by our moderately affected sample. Expected correlation between self-reported variables and measured physical capacity is another likely explanation for our results.

Relations between physical activity, fatigue and disease activity in people with RA are complex. Additional factors such as sleep and pain contribute, directly or indirectly, to the burden of fatigue [39]. High levels of fatigue reduce participation in physical activity [40], while on the other hand physical activity has the potential to reduce fatigue $[13,14,41]$. Similarly, there is no evidence of physical activity increasing disease activity, which may rather be reduced following exercise [42]. However, disease severity with widespread joint involvement might still limit physical activity [40].

The strongest associations with fatigue were found for anxiety/depression in both models explored in the present study. This is consistent with previous studies demonstrating mood disorders to have both a direct and indirect effect on fatigue in persons with RA [10, 43]. Since physical activity is important in the non-pharmacological treatment of depression [44], our results reinforce the importance of incorporating PA in the treatment of both depression and fatigue in RA.

Increased oxygen consumption, and the consequence metabolic cost, has previously been suggested as one plausible link to fatigue in RA [45]. In our study, the absence of associations, between fatigue and physical capacity, might be explained by our relatively fit sample compared to other RA samples, and values close to those of healthy individuals [46]. However, this result is somewhat puzzling since none of the participants fulfilled criteria for maintained ( $\geq 6$ months) levels of health-enhancing physical activity [24]. 
Table 3 Outcome of logistic regression for severe fatigue with odds ratios (OR) and 95\% confidence intervals (CI) for 1 $\mathrm{SD}$ increase in each predictor variable

\begin{tabular}{llcllc}
\hline Model A & OR $(95 \%$ CI $)$ & $p$ value & Model B & OR $(95 \%$ CI $)$ & $p$ value \\
\hline Disease duration $^{\mathrm{a}}$ & $0.97(0.93,1.01)$ & 0.169 & Disease duration $^{\mathrm{a}}$ & $0.97(0.93,1.02)$ & 0.277 \\
Biological drugs $^{\mathrm{b}}$ & $0.84(0.37,1.92)$ & 0.679 & Biological drugs $^{\mathrm{b}}$ & $0.86(0.36,2.08)$ & 0.742 \\
Comorbidities $^{\mathrm{c}}$ & $1.73(0.81,3.71)$ & 0.160 & Comorbidities $^{\mathrm{c}}$ & $2.05(0.92,4.59)$ & 0.079 \\
Activity limitation $^{\mathrm{d}}$ & $1.29(0.53,3.17)$ & 0.571 & Activity limitation $^{\mathrm{d}}$ & $2.24(0.83,6.1)$ & 0.113 \\
Health $^{\mathrm{e}}$ & $1.07(1.04,1.11)$ & $<0.0001$ & Health $^{\mathrm{e}}$ & $1.08(1.04,1.12)$ & $<0.0001$ \\
Pain $^{\mathrm{f}}$ & $1.04(1.02,1.07)$ & 0.002 & Pain $^{\mathrm{f}}$ & $1.04(1.01,1.07)$ & 0.004 \\
Anxiety/depression $^{\mathrm{g}}$ & $2.43(1.2,4.94)$ & 0.014 & Anxiety/depression $^{\mathrm{g}}$ & $2.58(1.25,5.32)$ & 0.011 \\
& & & Grip strength $^{\mathrm{h}}$ & $1(1,1.01)$ & 0.167 \\
& & & Lower limb function $^{\mathrm{i}}$ & $0.95(0.91,1)$ & 0.051 \\
& & & Aerobic capacity & $1.02(0.96,1.08)$ & 0.608 \\
\hline
\end{tabular}

Results produced using R, package mice [33]

Model A includes disease-related and perceived disease impact variables and Model B also includes physical capacity variables $(n=269)$

Pooled likelihood ratio test to compare models $=2.65, p=0.048$

${ }^{a}$ Disease duration, years

${ }^{\mathrm{b}}$ Medication with biological drug, yes vs no

${ }^{\mathrm{c}}$ Comorbidities, yes vs no

${ }^{\mathrm{d}}$ Activity limitation, $0-3$

${ }^{\text {e}}$ Perceived health, $0-100$

${ }^{\text {fPain, } 0-100}$

${ }^{\mathrm{g}}$ Anxiety/depression, 1-3

${ }^{\mathrm{h}}$ Grip strength, $\mathrm{N}$

${ }^{\mathrm{i}}$ Lower limb function, $\mathrm{s}$

${ }^{\mathrm{j}}$ Aerobic capacity, $\mathrm{ml} \times \mathrm{kg}^{1} \times \min ^{1}$
The major strengths of our study are the well-defined sample, our use of validated self-report questionnaires and capacity measures, and that the physical therapists conducting the capacity tests were trained to adhere to established test procedures. However, our assessment of fatigue with the use of a single-item measure, reflecting a global perspective of fatigue rather than a more multidimensional [47] may be questioned. On the other hand, the VAS was among the six questionnaires to assess fatigue recommended by the OMERACT 8 in 2006 when fatigue was included in the recommended core set for studies of persons with RA [48]. Another potential methodological bias might be our choice of a cut-off for severe fatigue that might be too low to result in convincing findings. However, the cut-off chosen is well documented and has been used in several previous studies [12, 49]. Furthermore, a higher cut-off for severe fatigue would have resulted in too small groups for statistically meaningful analyses in the present sample. Another possible limitation might be our use of self-reported physical activity that may be influenced by e.g., recall bias and social desirability. However, it is easy, affordable, and therefore, feasible for large groups of people. Objective recording of physical activity has become more feasible and affordable, but might still suffer from certain validity issues caused by limited wear time; periods during which participants, due to social desirability, might assume different physical activity patterns than their normal ones. Furthermore, possible selection bias cannot be excluded since overrepresentation of people interested in physical activity and underrepresentation of those with less interest, and maybe higher levels of fatigue. This potential threat to external validity should be considered when interpreting our results.

Fatigue in RA is complex and includes both biological and psychological aspects contributing to its burden on individuals $[8,39]$. Additionally, potentially coexisting conditions such as chronic fatigue syndrome, low vitamin D level, osteoporosis and infectious diseases also include a panorama of symptoms comprising fatigue. Neither biological mechanisms behind fatigue in RA nor differences and similarities in origin of fatigue compared to other conditions are completely defined. While exploration of such coexisting reasons for fatigue were beyond the scope of our study, they should be included in future studies to contribute to a more complete understanding of fatigue.

Since our study was cross-sectional, future longitudinal studies with repeated measures of fatigue to explore causation and identify predictors of fatigue are needed [9]. Further, the use of a multidimensional assessment of fatigue has the potential to increase our understanding of the role of physical capacity in explaining components of fatigue, e.g., 
mental and physical, and should be considered for inclusion in future studies on explanation of fatigue. This should preferably be done in large samples and with more physical capacity variables. In future studies, including physical capacity, we also suggest that the calculation of estimated maximal oxygen uptake based on the submaximal Astrand test [33] should be replaced by other algorithms that may be more accurate for the RA population [50].

\section{Conclusions}

Our results indicate that severe fatigue in people with RA is associated with self-rated health, pain and anxiety/depression rather than with physical capacity. Future studies should be prospective and use multidimensional assessments of fatigue to explore the influence of physical capacity on physical and mental fatigue, respectively, and the possible influence of comorbidities associated with fatigue should be controlled for.

Acknowledgements We thankfully acknowledge the participants for their time and effort and the support from professor Staffan Lindblad and the Swedish Rheumatology Quality Registers for providing access to data. The independent assessors of the PARA Study Group: physical therapists Christina Eriksson and Malin Wisell, Linköping University Hospital, Linköping; Birgitta Folin and Helena Heldt, Linköping University Hospital, Norrköping; Anna Moberg and Hanna Olsson, Mälarsjukhuset, Eskilstuna; Anna Hallén and Sofia Sandström, Karolinska University Hospital, Solna; Anna Dahlgren and Åsa Lindkvist, Karolinska University Hospital, Huddinge; Erica Christensen, Elin Löfberg and Sara Stråt, Danderyd University Hospital, Stockholm; Maria Skogemyr, Östersund Hospital; and Sofia Blomqvist, Sunderby Hospital, Luleå.

Author contributions SP: study design, interpretation of data, manuscript writing. ID: study design, statistical analysis, interpretation of data, manuscript writing. BN: data collection, manuscript writing/ approval. ABD: statistical analysis, manuscript writing/approval. $\mathrm{CHO}$ : study design, data collection, interpretation of data, manuscript writing.

Funding We gratefully acknowledge the financial support from Combine Sweden, the National Postgraduate School of Health Care Sciences, the Strategic Research Program in Health Care Science, the Swedish Research Council and the Swedish Rheumatism Foundation.

\section{Compliance with ethical standards}

Conflict of interest The authors declare no conflicts of interests.

Open Access This article is distributed under the terms of the Creative Commons Attribution 4.0 International License (http://creativeco mmons.org/licenses/by/4.0/), which permits unrestricted use, distribution, and reproduction in any medium, provided you give appropriate credit to the original author(s) and the source, provide a link to the Creative Commons license, and indicate if changes were made.

\section{References}

1. Anderson J, Caplan L, Yazdany J, Robbins ML, Neogi T, Michaud K, Saag KG, O’Dell JR, Kazi S (2012) Rheumatoid arthritis disease activity measures: American College of Rheumatology recommendations for use in clinical practice. Arthritis Care Res (Hoboken) 64:640-647. https://doi.org/10.1002/acr.21649

2. Norton S, Fu B, Scott DL, Deighton C, Symmons DP, Wailoo AJ, Tosh J, Lunt M, Davies R, Young A, Verstappen SM (2014) Health Assessment Questionnaire disability progression in early rheumatoid arthritis: systematic review and analysis of two inception cohorts. Semin Arthritis Rheum 44:131-144. https://doi. org/10.1016/j.semarthrit.2014.05.003

3. Pytel A, Demczyszak I, Sutkowska E, Rosinczuk J, Kuberka I, Koltuniuk A (2017) Knowledge and selected variables as determinants of the quality of life and general health of patients with rheumatoid arthritis. Adv Clin Exp Med 26:1411-1418. https:// doi.org/10.17219/acem/68900

4. Ahlstrand I, Thyberg I, Falkmer T, Dahlstrom O, Bjork M (2015) Pain and activity limitations in women and men with contemporary treated early RA compared to 10 years ago: the Swedish TIRA project. Scand J Rheumatol 44:259-264. https://doi. org/10.3109/03009742.2014.997285

5. Ishiguro N, Dougados M, Cai Z, Zhu B, Ishida M, Sato M, Gaich C, Quebe A, Stoykov I, Tanaka Y (2018) Relationship between disease activity and patient-reported outcomes in rheumatoid arthritis: Post hoc analyses of overall and Japanese results from two phase 3 clinical trials. Mod Rheumatol. https://doi. org/10.1080/14397595.2017.1422232

6. Repping-Wuts H, Uitterhoeve R, van Riel P, van Achterberg T (2008) Fatigue as experienced by patients with rheumatoid arthritis (RA): a qualitative study. Int J Nurs Stud 45:995-1002. https:// doi.org/10.1016/j.ijnurstu.2007.06.007

7. Morris G, Berk M, Galecki P, Walder K, Maes M (2016) The neuro-immune pathophysiology of central and peripheral fatigue in systemic immune-inflammatory and neuro-immune Diseases. Mol Neurobiol 53:1195-1219. https://doi.org/10.1007/s1203 5-015-9090-9

8. Hewlett S, Chalder T, Choy E, Cramp F, Davis B, Dures E, Nicholls C, Kirwan J (2011) Fatigue in rheumatoid arthritis: time for a conceptual model. Rheumatology 50:1004-1006. https://doi. org/10.1093/rheumatology/keq282

9. Nikolaus S, Bode C, Taal E, van de Laar MA (2013) Fatigue and factors related to fatigue in rheumatoid arthritis: a systematic review. Arthritis Care Res (Hoboken) 65:1128-1146. https://doi. org/10.1002/acr.21949

10. Nicassio PM, Ormseth SR, Custodio MK, Irwin MR, Olmstead $\mathrm{R}$, Weisman MH (2012) A multidimensional model of fatigue in patients with rheumatoid arthritis. J Rheumatol 39:1807-1813. https://doi.org/10.3899/jrheum.111068

11. Taylor P, Manger B, Alvaro-Gracia J, Johnstone R, Gomez-Reino J, Eberhardt E, Wolfe F, Schwartzman S, Furfaro N, Kavanaugh A (2010) Patient perceptions concerning pain management in the treatment of rheumatoid arthritis. J Int Med Res 38:1213-1224. https://doi.org/10.1177/147323001003800402

12. Pollard LC, Choy EH, Gonzalez J, Khoshaba B, Scott DL (2006) Fatigue in rheumatoid arthritis reflects pain, not disease activity. Rheumatology 45:885-889. https://doi.org/10.1093/rheumatolo gy/kel021

13. Cramp F, Hewlett S, Almeida C, Kirwan JR, Choy EH, Chalder T, Pollock J, Christensen R (2013) Non-pharmacological interventions for fatigue in rheumatoid arthritis. Cochrane Database Syst Rev 8:CD008322. https://doi.org/10.1002/14651858.CD008322. pub2 
14. Rongen-van Dartel SA, Repping-Wuts H, Flendrie M, Bleijenberg G, Metsios GS, van den Hout WB, van den Ende CH, Neuberger G, Reid A, van Riel PL, Fransen J (2015) Effect of aerobic exercise training on fatigue in rheumatoid arthritis: a meta-analysis. Arthritis Care Res (Hoboken) 67:1054-1062. https://doi. org/10.1002/acr.22561

15. Perandini LA, de Sa-Pinto AL, Roschel H, Benatti FB, Lima FR, Bonfa E, Gualano B (2012) Exercise as a therapeutic tool to counteract inflammation and clinical symptoms in autoimmune rheumatic diseases. Autoimmun Rev 12:218-224. https://doi. org/10.1016/j.autrev.2012.06.007

16. Hurkmans E, van der Giesen FJ, Vliet Vlieland TP, Schoones J, Van den Ende EC (2009) Dynamic exercise programs (aerobic capacity and/or muscle strength training) in patients with rheumatoid arthritis. Cochrane Database Syst Rev. https://doi. org/10.1002/14651858.CD006853.pub2

17. Kamwendo K, Askenbom M, Wahlgren C (1999) Physical activity in the life of the patient with rheumatoid arthritis. Physiother Res Int 4:278-292

18. Munsterman T, Takken T, Wittink H (2013) Low aerobic capacity and physical activity not associated with fatigue in patients with rheumatoid arthritis: a cross-sectional study. J Rehabil Med 45:164-169. https://doi.org/10.2340/16501977-1073

19. Arnett FC, Edworthy SM, Bloch DA, McShane DJ, Fries JF, Cooper NS, Healey LA, Kaplan SR, Liang MH, Luthra HS et al (1988) The American Rheumatism Association 1987 revised criteria for the classification of rheumatoid arthritis. Arthritis Rheum 31:315-324

20. Nordgren B, Friden C, Demmelmaier I, Bergstrom G, Lundberg IE, Dufour AB, Opava CH, Group PS (2015) An outsourced health-enhancing physical activity programme for people with rheumatoid arthritis: exploration of adherence and response. Rheumatology 54:1065-1073. https://doi.org/10.1093/rheumatolo gy/keu 444

21. Nordgren B, Friden C, Demmelmaier I, Opava CH (2014) Who makes it to the base? Selection procedure for a physical activity trial targeting people with rheumatoid arthritis. Arthritis Care Res (Hoboken) 66:662-670. https://doi.org/10.1002/acr.22189

22. Demmelmaier I, Bergman P, Nordgren B, Jensen I, Opava CH (2013) Current and maintained health-enhancing physical activity in rheumatoid arthritis: a cross-sectional study. Arthritis Care Res 65:1166-1176. https://doi.org/10.1002/Acr.21951

23. Fries JF, Spitz P, Kraines RG, Holman HR (1980) Measurement of patient outcome in arthritis. Arthritis Rheum 23:137-145

24. Haskell WL, Lee IM, Pate RR, Powell KE, Blair SN, Franklin BA, Macera CA, Heath GW, Thompson PD, Bauman A, American Heart A (2007) American College of Sports M. Physical activity and public health: updated recommendation for adults from the American College of Sports Medicine and the American Heart Association. Circulation 116:1081-1093. https://doi.org/10.1161/ CIRCULATIONAHA.107.185649

25. Wolfe F (2004) Fatigue assessments in rheumatoid arthritis: comparative performance of visual analog scales and longer fatigue questionnaires in 7760 patients. J Rheumatol 31:1896-1902

26. Craig CL, Marshall AL, Sjostrom M, Bauman AE, Booth ML, Ainsworth BE, Pratt M, Ekelund U, Yngve A, Sallis JF, Oja P (2003) International physical activity questionnaire: 12-country reliability and validity. Med Sci Sports Exerc 35:1381-1395. https ://doi.org/10.1249/01.MSS.0000078924.61453.FB

27. The IPAQ group (2010) The International Physical Activity Questionnaire (Guidelines for data processing and analysis of the International Physical Activity Questionnaire). http://www.IPAQ.ki.se. Accessed 2 Nov 2017

28. Burbank PM, Riebe D (2002) Promoting exercise and behavior change in older adults: interventions with the transtheoretical model. Springer, New York
29. Felson DT, Anderson JJ, Boers M, Bombardier C, Chernoff M, Fried B, Furst D, Goldsmith C, Kieszak S, Lightfoot R et al (1993) The American College of Rheumatology preliminary core set of disease activity measures for rheumatoid arthritis clinical trials. The Committee on Outcome Measures in Rheumatoid Arthritis Clinical Trials. Arthritis Rheum 36:729-740

30. Brooks RG, Jendteg S, Lindgren B, Persson U, Bjork S (1991) EuroQol: health-related quality of life measurement. Results of the Swedish questionnaire exercise. Health Policy 18:37-48

31. Csuka M, McCarty DJ (1985) Simple method for measurement of lower extremity muscle strength. Am J Med 78:77-81

32. Nordenskiold UM, Grimby G (1993) Grip force in patients with rheumatoid arthritis and fibromyalgia and in healthy subjects. A study with the Grippit instrument. Scand J Rheumatol 22:14-19

33. Astrand I (1960) Aerobic work capacity in men and women with special reference to age. Acta Physiol Scand Suppl 49:1-92

34. van Buuren S, Groothuis-Oudshoorn K (2011) Mice: multivariate imputation by chained equations in R. J Stat Softw 45:1-67. https://doi.org/10.18637/jss.v045.i03

35. Meng X-L, Rubin DB (1992) Performing likelihood ratio tests with multiply-imputed data sets. Biometrika 79:103-111. https ://doi.org/10.1093/biomet/79.1.103

36. Thyberg I, Hass UA, Nordenskiold U, Gerdle B, Skogh T (2005) Activity limitation in rheumatoid arthritis correlates with reduced grip force regardless of sex: the Swedish TIRA project. Arthritis Rheum 53:886-896. https://doi.org/10.1002/ art. 21595

37. Olsen CL, Lie E, Kvien TK, Zangi HA (2016) Predictors of fatigue in rheumatoid arthritis patients in remission or in a low disease activity state. Arthritis Care Res (Hoboken) 68:10431048. https://doi.org/10.1002/acr.22787

38. Weinstein AA, Drinkard BM, Diao G, Furst G, Dale JK, Straus SE, Gerber LH (2009) Exploratory analysis of the relationships between aerobic capacity and self-reported fatigue in patients with rheumatoid arthritis, polymyositis, and chronic fatigue syndrome. PM R 1:620-628. https://doi.org/10.1016/j.pmrj.2009.04.007

39. Rongen-van Dartel SA, Repping-Wuts H, Donders R, van Hoogmoed D, Knoop H, Bleijenberg G, van Riel PL, Fransen J (2016) A multidimensional 'path analysis' model of factors explaining fatigue in rheumatoid arthritis. Clin Exp Rheumatol 34:200-206

40. Loppenthin K, Esbensen BA, Ostergaard M, Jennum P, Tolver A, Aadahl M, Thomsen T, Midtgaard J (2015) Physical activity and the association with fatigue and sleep in Danish patients with rheumatoid arthritis. Rheumatol Int 35:1655-1664. https://doi. org/10.1007/s00296-015-3274-5

41. Neill J, Belan I, Ried K (2006) Effectiveness of non-pharmacological interventions for fatigue in adults with multiple sclerosis, rheumatoid arthritis, or systemic lupus erythematosus: a systematic review. J Adv Nurs 56:617-635. https://doi.org/10.111 1/j.1365-2648.2006.04054.x

42. Sveaas SH, Smedslund G, Hagen KB, Dagfinrud H (2017) Effect of cardiorespiratory and strength exercises on disease activity in patients with inflammatory rheumatic diseases: a systematic review and meta-analysis. Br J Sports Med 51:1065-1072. https ://doi.org/10.1136/bjsports-2016-097149

43. Minnock P, Veale DJ, Bresnihan B, FitzGerald O, McKee G (2015) Factors that influence fatigue status in patients with severe rheumatoid arthritis (RA) and good disease outcome following 6 months of TNF inhibitor therapy: a comparative analysis. Clin Rheumatol 34:1857-1865. https://doi.org/10.1007/s1006 7-015-3088-6

44. Cooney GM, Dwan K, Greig CA, Lawlor DA, Rimer J, Waugh FR, McMurdo M, Mead GE (2013) Exercise for depression. Cochrane Database Syst Rev 9:CD004366. https://doi.org/10.1002/14651 858.CD004366.pub6 
45. de Carvalho MR, Tebexreni AS, Salles CA, Barros Neto T, Natour $\mathrm{J}$ (2004) Oxygen uptake during walking in patients with rheumatoid arthritis-a controlled study. J Rheumatol 31:655-662

46. Ekdahl C, Broman G (1992) Muscle strength, endurance, and aerobic capacity in rheumatoid arthritis: a comparative study with healthy subjects. Ann Rheum Dis 51:35-40

47. Rupp I, Boshuizen HC, Jacobi CE, Dinant HJ, van den Bos GA (2004) Impact of fatigue on health-related quality of life in rheumatoid arthritis. Arthritis Rheum 51:578-585. https://doi. org/10.1002/art.20539

48. Kirwan JR, Minnock P, Adebajo A, Bresnihan B, Choy E, de Wit M, Hazes M, Richards P, Saag K, Suarez-Almazor M, Wells G, Hewlett S (2007) Patient perspective: fatigue as a recommended patient centered outcome measure in rheumatoid arthritis. J Rheumatol 34:1174-1177

49. Feldthusen C, Grimby-Ekman A, Forsblad-d'Elia H, Jacobsson L, Mannerkorpi K (2016) Seasonal variations in fatigue in persons with rheumatoid arthritis: a longitudinal study. BMC Musculoskelet Disord 17:59. https://doi.org/10.1186/s12891-016-0911-4

50. Nordgren B, Friden C, Jansson E, Osterlund T, Grooten WJ, Opava CH, Rickenlund A (2014) Criterion validation of two submaximal aerobic fitness tests, the self-monitoring Foxwalk test and the Astrand cycle test in people with rheumatoid arthritis. BMC Musculoskelet Disord 15:305. https://doi. org/10.1186/1471-2474-15-305 